\title{
Investigation of the Ankle Foot Orthoses Footplates Stiffness
}

\author{
Aurelijus DOMEIKA*, Vytautas GRIGAS**, Danguolè SATKUNSKIENE****, \\ Deividas S̆ATIKAS****, Ieva ALEKNAITÉ-DAMBRAUSKIENË***** \\ *Kaunas University of Technology, Studentu 56, LT-51424 Kaunas, Lithuania, E-mail: aurelijus.domeika@ktu.lt \\ **Kaunas University of Technology, Studentu 56, LT-51424 Kaunas, Lithuania, E-mail: vytautas.grigas@ktu.lt \\ ***Lithuanian Sports University, Sporto 6, LT-44221 Kaunas, Lithuania, E-mail: danguole.satkunskiene@lsu.lt \\ ****Baltic Orthoservice, UAB, Taikos 131A, LT-51124 Kaunas, Lithuania, E-mail: deividas.satikas@orthobaltic.lt \\ *****Kaunas University of Technology, Studenty 56, LT-51424 Kaunas, Lithuania, E-mail: alek.ieva@gmail.com \\ cross $^{\text {ref }}$ http://dx.doi.org/10.5755/j01.mech.23.6.16901
}

\section{Introduction}

One of the most important features to ensure person's socialization is the ability to walk. It depends on a proper functioning of several systems in human organism, where one of them is the apparatus of movement, namely lower limbs. However, problems may appear in both bones, also joints and muscles or even neural system. A quite frequent Foot drop, which is the inability to lift the front part of the foot, causes the toes to drag along the ground while walking. Afore mentioned movement disorder can happen at any age and affect either one or both feet at the same time. Foot drop may be caused by various reasons: muscle weakness, peripheral nerve problems or neuropathy, brain and spinal cord disorders [1, 2], therefore the treatment methods of the foot drop vary accordingly. Orthoses (AFO - ankle foot orthoses, or foot-drop braces) [3, 4] are quite widely used besides the surgical and medical treatment, especially as there are many different designs - rigid and flexible, solid and composed (two parts connected by hinges, being either passive or active; the latter allows the control of mutual position of AFO's foot and calf parts), one or two ankle joint sided, made of metal, plastics or carbon fiber etc.

Every therapeutic measure, including AFOs, is the most effective when designed and manufactured individually for the particular case on the basis of patient's anthropometrical data, disorder character etc. (not to mention universal models). Various researches of children and adult patients gait proved that AFO's efficiency mostly depends on its stiffness (or rigidity), what is usually evaluated based on the energy cost [5-8] or walking performance [9-12]. The same approach is also used when developing exoskeletons [13, 14]. The above mentioned researches and AFOs stiffness investigations under static [15-19] and dynamic [20, 21] loading lead us to the conclusion, that along with AFOs overall parameters (strength, longevity, comfort and ease of use etc.), their stiffness has a special interest of their manufacturers and therapists.

However, when performing the above mentioned researches, mostly the overall AFO stiffness in two-three ankle motion planes (Dorsiflexion/ Plantarflexion, Inversion/Eversion, Adduction/Abduction) is investigated. For that purpose, various apparatus [22-24] and computational models $[25,26]$ are developed. In some cases, the number of freedom degrees reaches 4-5 (torsional stiffness etc. is analyzed), but only Bregman et al [16] has used a method evaluating orthoses stiffness not only around the ankle joint but also metatarsal-phalangeal joint. The method refers to the original stiffness tester BRUCE (Biarticular reciprocating universal compliance estimator) designed on the basis of a replicated and manually driven human leg, which continuously registers joint configuration and force exerted by the AFO into the device. This approach is more adequate to the human feet specific structure and behavior, although the specialized standards like ISO 22523:2006(en) (Requirements and test methods for External limb prostheses and external orthoses) and ISO 22675:2016(en) (Prosthetics - Testing of ankle-foot devices and foot units - Requirements and test methods) do not contain any requirements for such devices footplate stiffness and describe mainly AFOs strength and durability testing.

It is known that functionality of every therapeutic or sports footwear depends on its sole stiffness quite toughly (except maybe stance phase). Results of the above mentioned gait researches as well as the increasing popularity of different design and destination shoes inserts or footplates [27-31] raise a question whether the AFO's footplate's (local) bending (in sagittal plane) stiffness has any influence on the functionality of such AFOs. Even the same type AFOs footplates (carbon fiber) have a different design, structure, shape and also dimensions (thickness), what directly affects the footplate's stiffness and herewith the efficiency of AFO. The absence of publications dedicated to research of this property of AFOs as well as information obtained from therapists allowed us to conclude that when prescribing a proper AFO for every patient (in case when universal model is used) or producing AFOs corresponding patient's individuality, only the overall (ankle joint) rigidity of the AFOs is usually taken into account.

Thus the aim of this research is to investigate the bending stiffness of several carbon fiber AFOs footplates and to perform a comparative analysis of these AFOs according to footplates bending stiffness. The research results provide the manufacturers and the customers of AFOs as well as therapists with additional information which would help them to improve their products functionality, efficiency and comfort.

\section{Methods and means}

The object of the research is five carbon-fiber AFO braces with lateral strut, (Fig. 1) where all of them are onepiece (with no hinges connecting metatarsal (foot) and 
proximal (calf) parts). In all cases the lateral strut is attached to the footplate at the same position - near $2 / 3 \mathrm{rds}$ of footplate chord. The main differences are in the shape or even more in structure of the footplate. AFO No.1 is one size smaller compared to AFOs No. 2 - No.4: its footplate length is $252 \mathrm{~mm}$ and maximal width $77 \mathrm{~mm}$ when average parameters of AFOs No. 2 - No.4 are $\sim 270 \mathrm{~mm}$ and $\sim 90$ $\mathrm{mm}$ respectively. Heel and toe ends of all AFOs footplates are basically round in plane with an exception of the AFO No. 2 which footplate has a tapered toe end. AFOs also differ by the plate's curvature (profile in longitudinal, sagittal plane section): four AFOs foot plates have two opposite direction bends, where one of them (AFO No. 1) is bent only once (toe end is raised only).

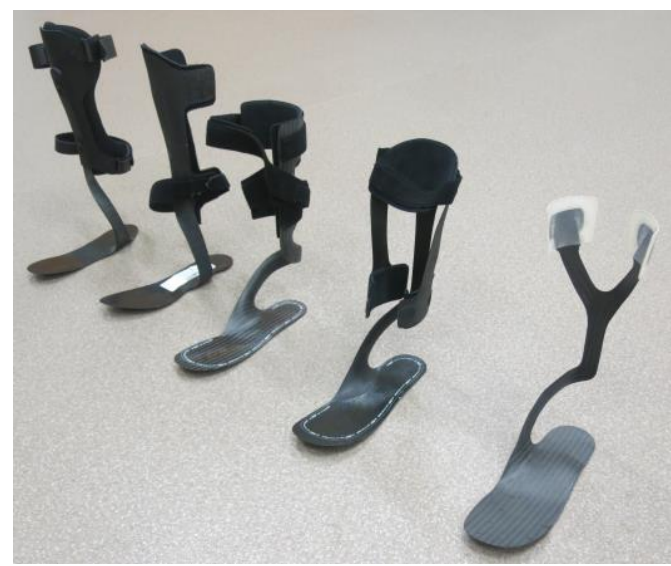

Fig. 1 Carbon-fiber AFO braces (No. 1-5 from the left to the right)

It is worth mentioning that all of the footplates significantly differ by the design and thickness. Some of them have almost constant thickness while some are composed of several layers of carbon fiber, thus being thicker at the middle and thinner near the perimeter or ends:

- almost all footplate of AFO No.1 has the same 2,0 $\mathrm{mm}$ thickness; only in the zone where lateral strut is attached it gradually increases up to $5.3 \mathrm{~mm}$ (size of such thick zone is near $50-60 \mathrm{~mm}$ );

- thickness of the AFO No.2 footplate is about $2.1 \mathrm{~mm}$; but it is reduced to $1 \mathrm{~mm}$ at the $10 \mathrm{~mm}$ with area by the perimeter. There is also $3 \mathrm{~mm}$ thickness and $28 \times 165 \mathrm{~mm}$ size zone in the middle of footplate;

- AFO No.3 footplate consists of 4 different thickness zones: the largest middle zone is $1.9 \mathrm{~mm}$ thick and thickness decreases to $1.5,1.2$ and $0.9 \mathrm{~mm}$ every $26 \mathrm{~mm}$ towards the end and every $17 \mathrm{~mm}$ towards heel;

- AFO No.4 footplate has also an inconstant thickness: $2.1,1.7,1.3$ and $0.9 \mathrm{~mm}$ which decreases accordingly by different length steps (33 mm towards the end and $14 \mathrm{~mm}$ towards heel);

- The structure of AFO's No.5 footplate is similar to AFOs No.3 and No.4: the largest middle zone is $2.0 \mathrm{~mm}$ thick and thickness decreases to $1.6,1.2$ and $0.8 \mathrm{~mm}$ every $26 \mathrm{~mm}$ towards the end and every $20 \mathrm{~mm}$ towards heel.

In order to evaluate the stiffness of the AFOs footplates each footplate was tested by the universal computerized dual column benchtop materials testing machine „Tinius Olsen H25KT“ (Tinius Olsen, USA) (Fig. 2), which was controlled by the software QMAT also used for processing measurements data [8].
Firstly, AFOs were mounted under the crosshead of testing machine immovably by tightening their footplates with the clamp to the top end of rigid holder attached to the bottom plate of testing machine. To apply the compressing load at different positions of the footplate, the holder was adjusted in respect of the frame of testing machine and thereby compressing tip attached to the bottom of the force sensor (Fig. 2).

The footplate deflection corresponding the displacement of crosshead of the machine and the resistance force arising due to elastic deformation of the footplate were measured synchronically by internal measurement system of the machine (1000 N capacity force sensor THE-1000N was used).

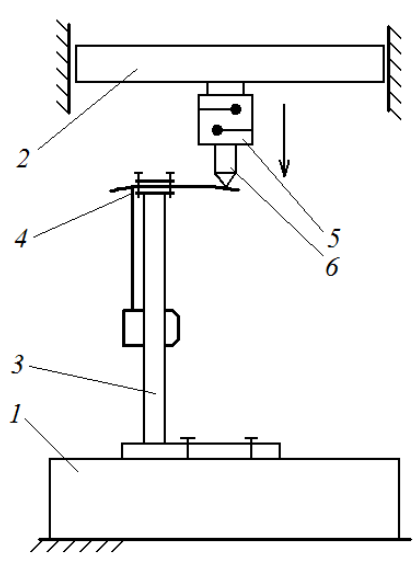

a b

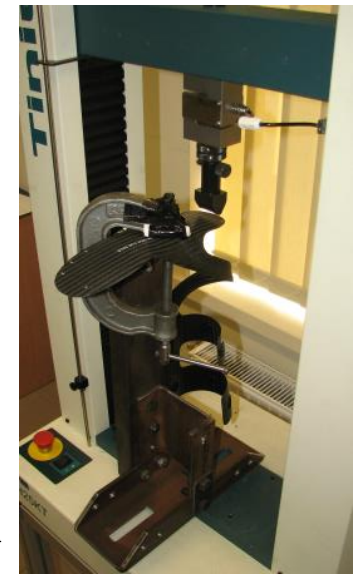

Fig. 2 Measurements of AFOs footplate stiffness: test rig scheme (a) and photo of (b): 1 - base of testing machine; 2 - crosshead of testing machine; 3 - adjusttable position holder; 4 - AFO; 5 - force sensor; 6 - compressing tip

Research was carried out considering the fact that human foot is more complex than the foot model analyzed by Bregman [16]. Many different multi-segment models of foot are used for gait and other type researches. The simplest Oxford Foot Model [32] consists of three segments, while the most complex model of the human foot developed by Anybody Modeling System has twenty-six segments [33], since it considers each bone as a rigid segment. A quite widely known five-segment foot model [34] was used as a reference for this research. According to this model the foot and ankle complex consists of the following segments: shank, hindfoot, midfoot, forefoot and toes which are connected by corresponding joints:

- midtarsal joint (MTJ);

- tarsometatarsal joint (TMTJ);

- metatarsophalangeal joint (MTPJ);

- proximal interphalangeal joint (PIPJ) of the hallux. To evaluate both the overall and local stiffness of AFOs footplate the measurements were carried out in two ways (Fig. 3):

- Overall stiffness due to the load acting at different distances $(10,40,70$ and $100 \mathrm{~mm})$ from the toe end and thereby from fixing point of the footplate where the lateral strut is attached. For this purpose, the position of entire holder/clamped AFO system was adjusted under the compressing tip while AFO's footplate was clamped to the 
holder the same way;

- Local stiffness due to the load acting at the same points as in previous case, but the footplate being clamped to the holder always at the same $30 \mathrm{~mm}$ distance from the compressing tip.

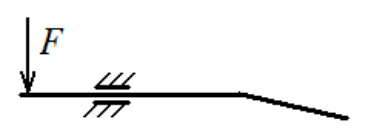

a

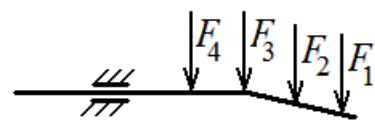

b
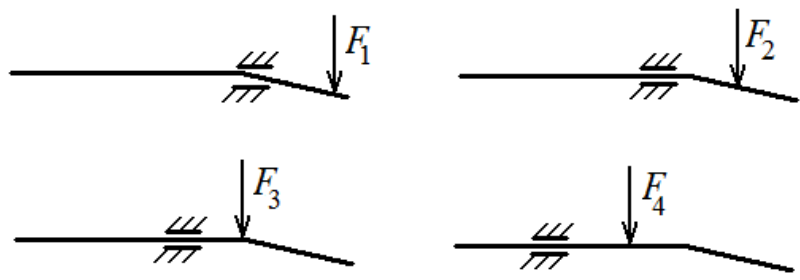

C

Fig. 3 Schemes of measurements of AFOs footplate stiffness: heel stiffness (a); toe end overall stiffness (b) and toe end local stiffness (c) (loading by force $F_{4}$ on schemes $\mathrm{b}$ and $\mathrm{c}$ is identical)

This way the loading points were approximately matched with the position of corresponding foot joints in the shoe: $10 \mathrm{~mm}$ from the footplate toe end - PIPJ, $40 \mathrm{~mm}-$ MTPJ, $70 \mathrm{~mm}$ - TMTJ and 100 - MTJ (corresponding forces $F_{1}, F_{2}, F_{3}$ and $F_{4}$ on loading schemes Fig. 3 b, and c). Additionally, the AFO footplate heel end stiffness was measured by loading footplate at $15 \mathrm{~mm}$ point from the heel end edge (loading scheme Fig. 3, a).

The dependencies of loading force on the crosshead travel or footplate deflection were obtained during the investigation. Based on afore mentioned dependencies the stiffness coefficients were calculated according to the equation $F=k \cdot x$, where $F$ is force, $k-$ stiffness coefficient and $x$-deformation (deflection) of the footplate (corresponding the compressing tip displacement). When describing the whole AFO stiffness (including shank part) usually the angular dimensions are used, namely the bending moment or angle, however in the case of footplate the linear stiffness seems to be more suitable. Due to relatively high flexibility of the footplates it was possible to load them quite significantly; however, in that case the analyzed structures would change into geometrically nonlinear because of the large displacements. Therefore, stiffness coefficient was calculated using force arising at 5 $\mathrm{mm}$ footplates deflection in case of heel stiffness measurements and $10 \mathrm{~mm}$ deflection with the measurements of toe end overall and local stiffness. The speed of materials testing machine crosshead and herewith footplate load increment was $40 \mathrm{~mm} / \mathrm{min}$, that is static stiffness characteristics were found during investigation.

\section{Results and discussion}

Loading force variation depending on different AFOs footplates deflection when measuring their overall stiffness is shown on Fig. 4, a. This corresponds to the case shown on Fig. 3, b (force $F_{2}$ ), when the load acts at $40 \mathrm{~mm}$ distance from the toe end and the footplate is clamped at the area where lateral strut is attached.

Variation of different AFOs footplates elastic deformation force when measuring local stiffness by applying load at the same $40 \mathrm{~mm}$ distance from the toe end but footplate being clamped at the $30 \mathrm{~mm}$ distance from the loading point (force $F_{2}$ on scheme Fig. 3, c) is shown on Fig. 4, b.

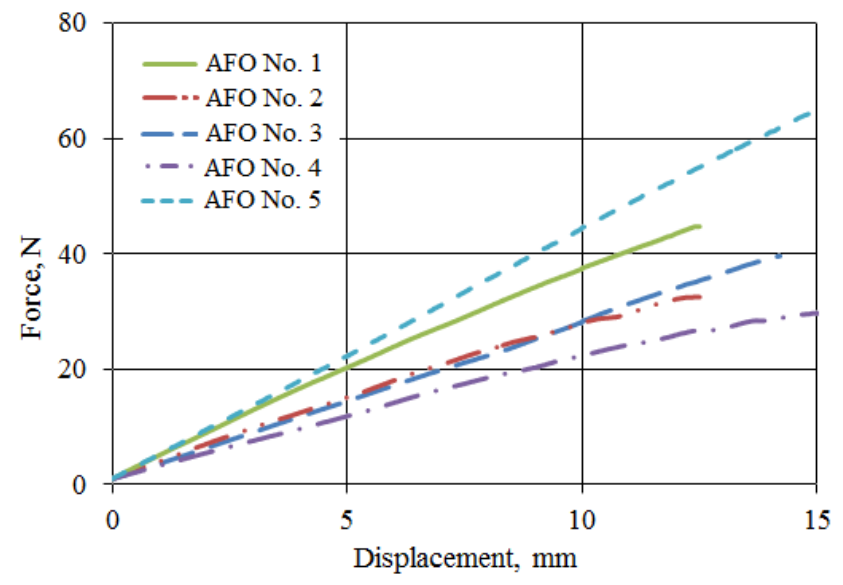

a

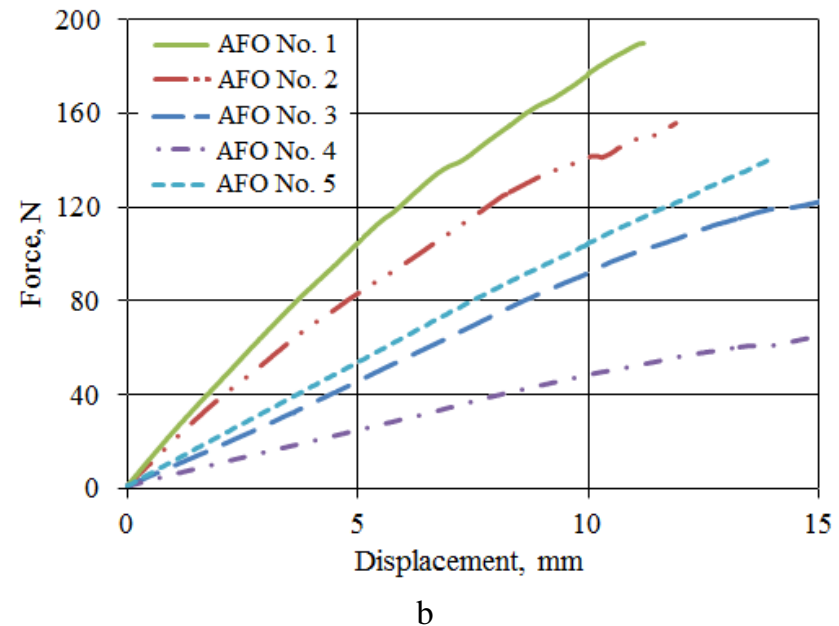

Fig. 4 Variation of the force caused by elastic deformation of different AFO's footplate when measuring overall stiffness (a); when measuring local stiffness (b) (in both cases load is applied at $40 \mathrm{~mm}$ distance from the toe end)

Fig. 5 shows variation of the force caused by elastic deformation of different AFO's footplates that appears when measuring their heel stiffness. In this case load was applied at the $15 \mathrm{~mm}$ distance from the heel end of the footplate which was clamped at the area where lateral strut is attached to the footplate (scheme Fig. 3, a).

As it was mentioned before (in section 2) stiffness coefficient $k$ was calculated to compare the functional properties of different AFO's in 40 cases of investigation: five AFOs, $2 \times 4$ combinations of toe end fixture/load position (one common for local and overall stiffness) and measurements of the heel stiffness for each AFO. Stiffness coefficient $k$ was calculated according to the equation $k=F / x$ based on the size of loading force $F$ arising at $10 \mathrm{~mm}$ reference displacement $x$ of compressing tip (or footplate deflection) for the toe end and $5 \mathrm{~mm}$ - for the heel end. 


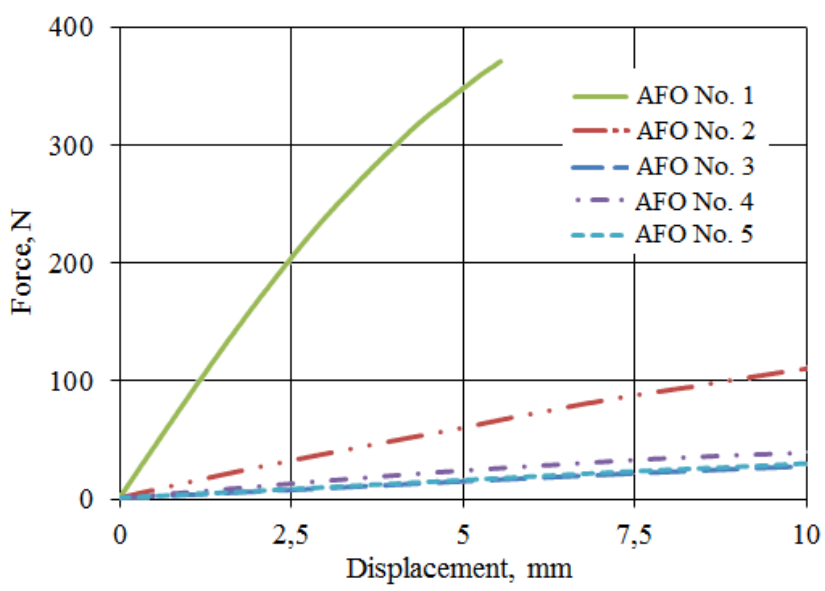

Fig. 5 Variation of the force caused by elastic deformation of different AFO's footplate when measuring heel stiffness

Variation of the footplate toe end overall stiffness coefficient which depends on the loading point position (or distance from the toe end, Fig. 3, b) is shown on Fig. 6, whereas Fig. 7 shows variation of the footplate toe end local stiffness coefficient (zones T1, T2, T3 and T4 correspond loading cases shown on Fig. 3, c) and heel stiffness coefficient (zone H5, loading case shown on Fig. 3, a) for all the examined AFOs.

It was found that force dependencies on the deflection up to either 5 or even $10 \mathrm{~mm}$ were close to linear almost in all of the examined cases (Figs. 4 and 5). However, that appears to be the only similarity of the analyzed AFO's, as the force range at $10 \mathrm{~mm}$ reference deflection clearly depends on AFO's footplate design and the combination of the fixture and loading points (i.e. the part of the footplate which stiffness was measured).

During the investigation of footplate overall stiffness (constant position of the footplate fixture and variable loading point) the force caused by elastic deformation has increased quite proportionally from the smallest when the length of bended structure was maximal (loading scheme Fig. 3, b, force $F_{1}$ ) (range from 7 to $17 \mathrm{~N}$ ) to the largest (range from 245 to $550 \mathrm{~N}$ ) when the length of bended structure was minimal (loading scheme Fig. 3, b, force $F_{4}$ ). Intermediate cases (loading scheme Fig. 3, b, forces $F_{2}$ and $F_{3}$ ) gave the transitional ranges of force correspondingly from 22 to $43 \mathrm{~N}$ and from 58 to $170 \mathrm{~N}$. Hence the overall stiffness of various AFO's differs more than two times (or even 3 times in the last case) irrespectively of the loading case.

The local stiffness investigation showed that the scatter of the force size at same deflection is even larger (loading schemes Fig. 3, c, and results - Fig. 7). In this case the force range was from 127 to $305 \mathrm{~N}$ (force $F_{3}$ ), from 47 to $173 \mathrm{~N}$ (force $F_{2}$ ) and from 16 to $178 \mathrm{~N}$ (force $F_{1}$ ) and differed even up to 10 times for every AFO the footplate toe end stiffness difference being the highest (Fig. 7, zone H5).

The variation of footplate toe end overall and local stiffness and its differences for examined AFOs are also clearly seen on Figs. 6 and 7. It may be seen that the overall stiffness of AFOs is practically the same $(0.88-2.04 \mathrm{~N} / \mathrm{mm})$ when the longest part of the footplate toe end is bended (force $F_{1}$ on scheme Fig. 3, b). The overall stiffness increases nearly twice (to $2,9-4,5 \mathrm{~N} / \mathrm{mm}$ ) when the load is applied $30 \mathrm{~mm}$ closer to the clamping point (force $F_{2}$ on scheme Fig. 3, b) but is still quite similar for all the AFOs. The further reduction of the distance between fixture and loading points leads to rapid growth of stiffness and its scatter $\left(6,8-18,3\right.$ and $28,4-57,6 \mathrm{~N} / \mathrm{mm}$ for forces $F_{3}$ and $F_{4}$ on scheme Fig. 3, b correspondingly). To conclude, the stiffness of AFO No. 5 was the largest in all cases, whereas the AFO No. 2 had the smallest overall stiffness. The overall stiffness coefficients of these two AFOs differ almost 2 times for loading cases $F_{3}$ and $F_{4}$ (scheme Fig. 3, b).

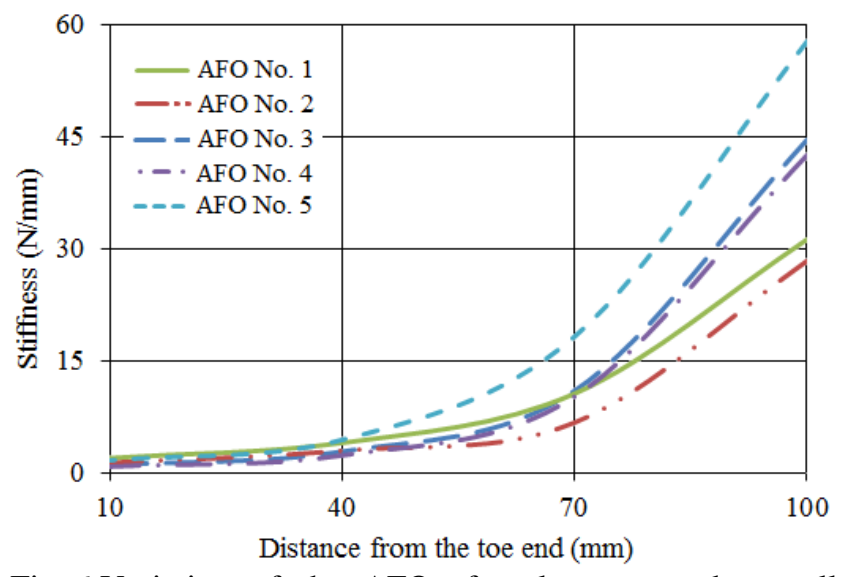

Fig. 6 Variation of the AFOs footplate toe end overall stiffness coefficient depending on loading point position (or distance from the toe end, loading scheme shown on Fig. 3, b)

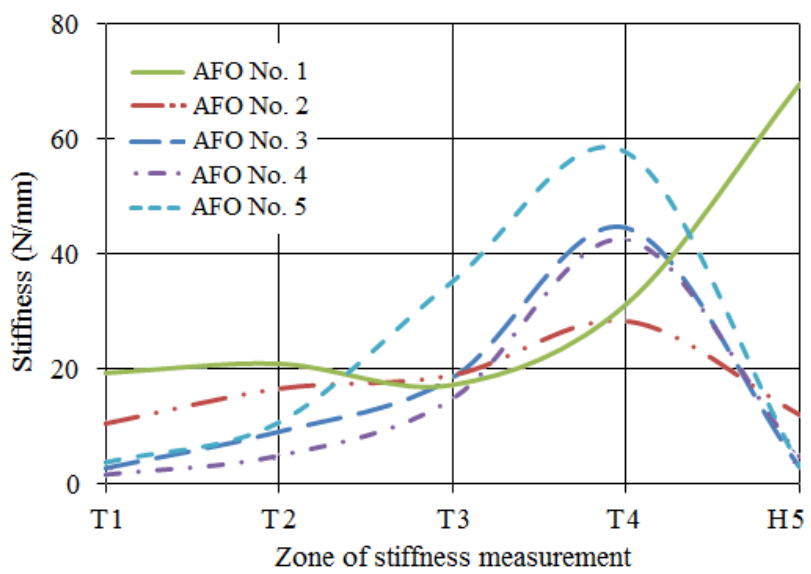

Fig. 7 Variation of the AFOs footplate toe end local stiffness coefficient (zones T1, T2, T3 and T4 correspond loading cases shown on Fig. 3, c) and heel stiffness coefficient (zone H5, loading case shown on Fig. 3, a)

Dissimilarities of AFO's footplate structure leaded to significant differences both in their overall stiffness and in the stiffness of local zones of these footplates (Fig.7, zones T1-T4). For example, AFO No. 1 and AFO No. 2 footplates have quite similar stiffness in all zones of toe end (varying from 20 to 31 and from 11 to $28 \mathrm{~N} / \mathrm{mm}$ correspondingly), whereas the stiffness of all the remaining AFO's footplates gradually increases when getting closer to the middle of the structure from 1,5 to 42,5 N/mm (AFO No. 4), 2,8 to $44,6 \mathrm{~N} / \mathrm{mm}$ (AFO No. 3 ) and 3,8 to $57,8 \mathrm{~N} / \mathrm{mm}$ (AFO No. 5).

AFOs footplates' heel stiffness also differs quite significantly depending on the footplate design (Fig. 5 and Fig. 7, zone 5). The heel of AFO No. 1 footplate is more than 20 times stiffer (stiffness coefficient equals $69,6 \mathrm{~N} / \mathrm{mm}$ ) compared to the footplates heels of AFO No. 3 
and No. 5 with stiffness coefficients 3 and $3,2 \mathrm{~N} / \mathrm{mm}$ respectively. AFO No. 2 footplate heel stiffness being 4 times larger than the latter two $(12,1 \mathrm{~N} / \mathrm{mm})$ is still around 7 times smaller than stiffness of AFO No. 1.

Based on the research results it may be stated that the overall and local stiffness of various designs AFO's footplates differ significantly (up to several times) and this will definitely affect the AFO's functionality. Same size but various footplate stiffness AFO's used by the patients with different biomechanical parameters (foot and the whole body) will also have a different effect on their gait, as the AFOs behavior (store and release elastic deformation energy during gait cycle) depends both on the patient's foot size and also on his weight, anthropometrical parameters, foot structure etc.

Thus in order to ensure maximal comfort, efficiency of treatment and shorter rehabilitation process such devices should be designed and manufactured according the peculiarities of patient and considering the rigidity of the whole $\mathrm{AFO}$ as well as stiffness of its footplate.

Investigation of the impact of AFO's footplate stiffness on gait performance was recently started in the biomechanics laboratory in KTU.

\section{Conclusions}

In can be concluded that AFO's stiffness has the most effect on their functionality, however the whole AFO's rigidity is usually taken into account. The results of experimental investigation of the overall and local stiffness of five different manufacturers carbon fiber AFO's footplates toe and heel ends showed that nearly same size AFO's footplates toe end different zones stiffness may differ 2-3 times and heel end stiffness differ even 7 times, what definitely will have a significant effect on the patient's gait parameters. The experimental and computational research aiming to check the impact of AFO's footplate stiffness on the gait performance is being carried out by the authors of this study and its primary results confirm the presumption.

Therefore, when designing and manufacturing AFO's for particular patient it is necessary to evaluate not only the overall rigidity of the whole AFO, but also its footplate stiffness, which should match patient's weight and lower body parameters including peculiarities of his foot.

\section{References}

1. The use of ankle foot orthoses in the management of stroke. 2008. Evidence Note Number 1. American Orthotic and Prosthetic Association, Inc. [online] [accessed 11 Oct. 2016]. Available from Internet: http://www.oandp.org/publications/evidencenotes/ AFOs_Management_Stroke.pdf

2. NHS choices. Foot drop. [online] [accessed 25 Sept. 2016]. Available from Internet: http://www.nhs.uk/ conditions/foot-drop/Pages /Introduction.aspx

3. Ottobock. Solution Overview. [online] [accessed 25 Sept. 2016]. Available from Internet: http://www. ottobockus.com/orthotics/solution-overview/

4. Ortho Baltic. Custom-made Pre-Preg Orthoses. [online] [accessed 18 Nov. 2016]. Available from Internet: http://www.orthobaltic.eu/orthoses.html
5. Bregman, D.J.; Harlaar, J; Meskers, C.G.; de Groot , V. 2012. Spring-like Ankle Foot Orthoses reduce the energy cost of walking by taking over ankle work. Gait Posture. 2012 Jan;35(1):148-53.

http://dx.doi:10.1016/j.gaitpost.2011.08.026.Epub 2011 Nov 1.

6. Bregman, D.J.; van der Krogt, M.M.; de Groot, V.; Harlaar, J.; Wisse, M.; Collins, S.H. 2011. The effect of ankle foot orthosis stiffness on the energy cost of walking: a simulation study. Clin Biomech (Bristol, Avon). 2011 Nov;26(9):955-61.

http://dx.doi doi: 10.1016/j.clinbiomech.2011.05.007. Epub 2011 Jun 30.

7. Bartonek, A.; Eriksson, M.; Gutierrez-Farewik, E.M. 2007. A new carbon fibre spring orthosis for children with plantarflexor weakness. Gait \& Posture 25 (2007) 652-656. https://doi.org/10.1016/j.gaitpost.2006.07.013.

8. Bartonek, A.; Eriksson, M.; Gutierrez-Farewik, E.M. 2007. Effects of carbon fibre spring orthoses on gait in ambulatory children with motor disorders and plantarflexor weakness. Developmental Medicine \& Child Neurology 2007, 49: 615-620. https://doi.org/10.1111/j.1469-8749.2007.00615.x.

9. Harper, N.G.; Russell Esposito, E.; Wilken, J.M.; Neptune, R.R. 2014. The influence of ankle-foot orthosis stiffness on walking performance in individuals with lower-limb impairments. Clinical Biomechanics 29 (2014), 877-884. https://doi.org/10.1016/j.clinbiomech.2014.07.005.

10. Russell Esposito, E.; Blanck, R.V.; Harper, N.G.; Hsu, J.R.; Wilken, J.M. 2014. How does ankle-foot orthosis stiffness affect gait in patients with lower limb salvage? Clin. Orthop. Relat. Res. 2014 Oct; 472(10): 3026-35. http://dx.doi doi: 10.1007/s11999-014-3661-3.

11. Singer, M.; Kobayahi, T.; Lincoln, L.; Orendurff, M.; Bo Foreman, K. 2014. The effect of AFO stiffness on the knee joint during the heel strike phase of gait in stroke patients., April 2014 The FASEB Journal, 28(1), Supplement 919.12.

12. Kerkum, Y.L.; Buizer, A.I.; van den Noort, J.C.; Becher, J.G.; Harlaar, J., Brehm, M-A. 2015. The Effects of Varying Ankle Foot Orthosis Stiffness on Gait in Children with Spastic Cerebral Palsy Who Walk with Excessive Knee Flexion. Published: November 23, 2015 doi.org/10.1371/journal.pone.0142878.

13. Collins, S.H.; Wiggin, M.B.; Sawicki, G.S. 2015. Reducing the energy cost of human walking using an unpowered exoskeleton. Nature 522: 212-215. http://dx.doi doi:10.1038/nature14288.

14. Gregorczyk, K.N.; Hasselquist, L.; Schiffman, J.M.; Bensel, C.K.; Obusek, J.P.; Gutekunst, D.J. 2010. Effects of a lower-body exoskeleton device on metabolic cost and gait biomechanics during load carriage. Ergonomics 53: 1263-75. http://dx.doi doi: 10.1080/00140139.2010. 512982.

15. Yamamoto, S.; Ebina, M.; Iwasaki, M.; Kubo, S.; Kawai, H.; Kayashi, T. 1993. Comparative study of mechanical characteristics of plastic AFOs. The American Academy of Orthotists \& Prosthetists. JPO, 5(2): 59-64.

16. Bregman, D.J.; $\quad$ Rozumalski, A.; $\quad$ Koops, D.; de Groot, V.; Schwartz, M.; Harlaar, J. 2009. A new 
method for evaluating ankle foot orthosis characteristics: BRUCE. Gait Posture. 2009 Aug;30(2):144-9.

http://dx.doi doi: 10.1016/j.gaitpost.2009.05.012.

17. Bielby, S.A.; Warrick, T.J.; Benson, D.; Brooks, R.E.; Skewes, E.; Alvarez, E.; Dunning, Ch.; DesJardins, J.D. 2010. Trimline Severity Significantly Affects Rotational Stiffness of Ankle-Foot Orthosis. The American Academy of Orthotists \& Prosthetists. JPO, 22(4): 204-210.

https://doi.org/10.1682/JRRD.2010.10.0193.

18. Kobayashi, T.; Leung, A.K.; Hutchins, S.W. 2011. Techniques to measure rigidity of ankle-foot orthosis: a review. J Rehabil Res Dev. 2011;48(5):565-76.

19. Munguia, J.; Dalgarno, K.W. 2013. Ankle foot orthotics optimization by means of composite reinforcement of free-form structures. 4th International Solid Freeform Fabrication Symposium. [online] [accessed 19 Oct. 2016].

Available from Internet:

http://sffsymposium.engr.utexas.edu/Manuscripts/2013/ 2013-61-Munguia.pdf

20. Takahashi, K.Z.; Stanhope, S.J. 2010. Estimates of Stiffness for Ankle-Foot Orthoses Are Sensitive to Loading Conditions. The American Academy of Orthotists \& Prosthetists. JPO, 22(4): 211-219.

21. Cappa, P.; Di Rosa, G.; Patanè, F. 2004. Dynamic measurement of 3-d stiffness of ankle-foot orthoses. [online] [accessed 06 Sept. 2016]. Available from Internet: https://sem.org/wp-content/uploads/2015/12/ sem.org-SEM-X-Int-Cong-s110p01-DynamicMeasurement-3-D-Stiffness-Ankle-foot-Orthoses.pdf

22. Cappa, P.; Patanè, F.; Pierro, M.M. 2003. A novel device to evaluate the stiffness of ankle-foot orthosis devices. J Biomech Eng. 2003 Dec;125(6):913-7. https://doi.org/10.1115/1.1634993.

23. Polliack, A.A.; Swanson, Ch.; Landsberger, S.E.; McNeal, D.R. 2001. Development of a Testing Apparatus for Structural Stiffness Evaluation of AnkleFoot Orthoses. The American Academy of Orthotists \& Prosthetists. JPO, 13(3): 74-82.

24. Cappa, P.; Patanè, F.; Di Rosa, G. 2005. A continuous loading apparatus for measuring three-dimensional stiffness of ankle-foot orthoses. J Biomech Eng. 2005 Nov;127(6):1025-9. https://doi.org/10.1115/1.2049313.

25. Uning, R.; Abu Osman, N.A.; Abdul Rahim, R.B. 2008. 3D Finite Element Analysis of Ankle-Foot Orthosis on Patients with Unilateral Foot Drop: A Preliminary Study. 4th Kuala Lumpur International Conference on Biomedical Engineering 2008, 21: 366369.

26. Zou, D.; He, T.; Dailey, M.; Smith, K.E.; Silva, M.J.; Sinacore, D.R.; Mueller, M.J.; Hastings, M.K. 2014. Experimental and computational analysis of composite ankle-foot orthosis. Journal of Rehabilitation Research \& Development, 51(10): 1525 - 1536. https://doi.org/10.1682/JRRD.2014-02-0046.

27. OrthoBaltic. Prefabricated footplates. [online] accessed 03 Nov. 2016].

Available from Internet:

http://www.orthobaltic.eu/footwear/prefabricatedfootplates.html
28. Myfootshop. Spring Plate - Carbon/graphite fiber insole. [online] accessed 03 Nov. 2016]. Available from Internet: http://www.myfootshop.com/spring-platecarbongraphite-fiber-insert

29. RTP Carbon Fiber Inserts. [online] accessed 04 Nov. 2016]. Available from Internet: http://www.rtpfast.com/products.html

30. Custom Composite. Carbon footplates. [online] accessed 18 Nov. 2016]. Available from Internet: http://www.cc-mfg.com/footplates.html

31. Ottobock. Carbon foot plates. [online] accessed 18 Nov. 2016]. Available from Internet: https://professionals.ottobockus.com/Orthotics/CustomOrthotics/AFO--Ankle-Foot-Orthosis/DynamicComponents/Carbon-Foot-Plates/c/4032

32. Carson, M.C.; Harrington, M.E.; Thompson, N.; O'Connor, J.J.; Theologis, T.N. 2001. Kinematic analysis of a multi-segment foot model for research and clinical applications: A repeatability analysis. Journal of Biomechanics, 34(10):1299-1307. https://doi.org/10.1016/S0021-9290(01)00101-4

33. Carbes, S.; Tørholm, S.; Telfer, S.; Woodburn, J.; Oosterwaal, M.; Rasmussen, J. 2011. A new multisegmental foot model and marker protocol for accurate simulation of the foot biomechanics during walking. Proc. of ISB 2011 Congress XXIII, 1-2 p.

34. Tome, J.; Nawoczenski, D.; Flemister, A.; Houck, J. 2006. Comparison of foot kinematics between subjects with posterior tibialis tendon dysfunction and healthy controls. The Journal of Orthopaedic and Sports Physical therapy, 36(9):635-644. https://doi.org/10.2519/jospt.2006.2293.

A. Domeika, V. Grigas, D. Satkunskienė, D. Šatikas, I. Aleknaitè-Dambrauskienè

\section{INVESTIGATION OF THE ANKLE FOOT ORTHOSES FOOTPLATES STIFFNESS}

S u m m a r y

Carbon fiber Ankle Foot Orthoses (AFOs) are widely used to help walking the patients having so called foot drop or similar diseases or just to improve walking performance. AFO's overall and its footplate stiffness's have the most effect on their functionality, however usually the whole AFO's rigidity is taken into account. The article describes the results of experimental investigation of the overall and local stiffness of five different manufacturers carbon fiber AFO's footplates toe and heel ends. It is shown that the near same size AFO's footplates toe end different zones stiffness may differ from 2 to 3 times and heel end stiffness even by 7 times, what would definitely have significant effect on the patient's gait parameters. Thus when designing and manufacturing AFO's dedicated to particular patient it is necessary to evaluate not only the overall rigidity of the whole AFO, but also its footplate stiffness.

Keywords: ankle foot orthoses, footplate, stiffness.

Received November 24, 2016 Accepted December 07, 2017 